\title{
GA-A16048
}

\section{ACQUISITION, ARCHIVING, AND ANALYSIS OF DOUBLET III DIAGNOSTIC DATA ON A DISTRIBUTED COMPUTER SYSTEM}

\author{
by \\ A. GLAD, P. HENLINE, B. McHARG, \\ D. DROBNIS, S. KARIN, and G. SHEPHARD
}

SEPTEMBER 1980 


\section{DISCLAIMER}

This report was prepared as an account of work sponsored by an agency of the United States Government. Neither the United States Government nor any agency Thereof, nor any of their employees, makes any warranty, express or implied, or assumes any legal liability or responsibility for the accuracy, completeness, or usefulness of any information, apparatus, product, or process disclosed, or represents that its use would not infringe privately owned rights. Reference herein to any specific commercial product, process, or service by trade name, trademark, manufacturer, or otherwise does not necessarily constitute or imply its endorsement, recommendation, or favoring by the United States Government or any agency thereof. The views and opinions of authors expressed herein do not necessarily state or reflect those of the United States Government or any agency thereof. 


\section{DISCLAIMER}

Portions of this document may be illegible in electronic image products. Images are produced from the best available original document. 
This report was prepared as an account of work sponsored by an agency of the United States Government. Neither the United States Government nor any agency thereof, nor any of their employees, makes any warranty, express or implied, or assumes any legal liability or responsibility for the accuracy, completeness, or usefulness of any information, apparatus, product, or process disclosed, or represents that its use would not infringe privately owned rights. Reference herein to any specific commercial product, process, or service by trade name, trademark, manufacturer, or otherwise, does not necessarily constitute or imply its endorsement, recommendation, or favoring by the United States Government or any agency thereof. The views and opinions of authors expressed herein do not necessarily state or reflect those of the United States Government or any agency thereof. 
GA-A16048

\title{
ACQUISITION, ARCHIVING, AND ANALYSIS OF DOUBLET III DIAGNOSTIC DATA ON A DISTRIBUTED COMPUTER SYSTEM
}

\author{
by \\ A. GLAD, P. HENLINE, B. MCHARG, \\ D. DROBNIS, S. KARIN, and G. SHEPHARD
}

This is a preprint of a paper to he presented at the Eleventh Symposium on Fusion Technology, September 15-19, 1980, Oxford, England.

\author{
Work Supported by \\ Department of Energy \\ Contract DE-AT03-76ET51011
}

GENERAL ATOMIC PROJECT 3235.803.202

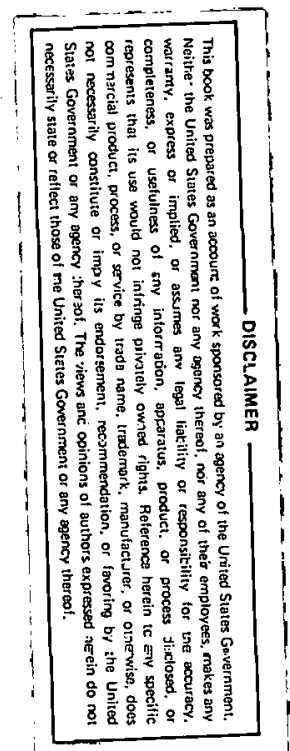
SEPTEMBER 1980

\section{GENERAL ATOMIC COMPANY}


ACQUISITION, ARCHIVING, AND ANALYSIS OF DOUBLET III DIAGNOSTIC

DATA ON A DISTRIBUTED COMPUTER SYSTEM*

A. Glad, P. Henline, B. McHarg, D. Drobnis, S. Karin, G. Shephard General Atomic Company

10955 John J. Hopkins Drive, San Diego, CA 92121, USA

\begin{abstract}
Computer support of a tokamak fusion experiment for the purpose of data acquisition, analysis, and archiving required handing the large amounts of data generated each shot, and presenting the data for both individual diagnostic experiments and shot summary in a timely and useful manner. A distributed computer system with processing at three levels supports General Atomic's Doublet III tokamak by providing: (1) acquisition and permanent archiving of all diagnostic data, (2) analysis and control for each physics diagnostic, (3) overall shot summary after each shot, and (4) detalled analysis of current and past shot data.

1. INTRODUCTION
\end{abstract}

This paper describes the diagnostic data acquisition, archiving and processing system for Doublet III, with emphasis on management of the large mass of diagnostic data through a distributed computing system. The number of diagnostics currently operating and planned required a system which provides concurrent acquisition and processing, and allows the addition of new diagnostics without unduly perturbing the existing system. In addition, generalized applications software tools were necessary for use by a variety of diagnostics. These are transferable from mlcroprocessor to minicomputer to large mainframe, allowing consistency and adaptability. of software. 


\section{CENTRALIZED MINICOMPUTER SYSTEM}

The centralized minicomputer system was designed and implemented to be the host computer, with responsiblities for acquisition and management of all Doublet III data. The minicomputer system design requirements were demanding and included the acquisition, processing and archiving of approximately two million samples of data over a shot cycle 4-7 minutes in length. In addition, flexibility was necessary to enable modifications reflecting rapidly changing physics diagnostics.

Three objectives were defined. The first was to acquire and manage all data for every physics diagnostic on the Doublet device. To do this, a centralized data acquisition system was designed using one set of services to acquire and manage all diagnostic data. The data acquired was of two types: 1) raw data from hardware devices such as waveform digitizers, analog-to-digital converters (ADCs), etc., which were acquired and managed directly by the minicomputer system, and 2) preprocessed data from microprocessors used to control and interface individual physics experiments.

The second objective was to archive all data for permanent storage and retrieval. An existing DECsystem-10 computer, which is part of the National Magnetic Fusion Energy (NMFE) computer network, was used. This allowed for post-shot analysis too elaborate to perform on the mini- or microcomputers within the shot time frame, as well as access to it through time-shared terminals and the NMFE computer network. The data archived includes both the raw or processed data acquired by the minicomputer system and all data base parameters necessary to interpret and process the data.

The third objective was to provide limited real-time analysis for each physics diagnostic. This analysis provides an indication of whether the diagnostic is functioning successfully and of overall plasma behavior. The analysis is distributed between the mini- and micro = systews to allow a large amount of output within the shot time. 


\subsection{Hardware configuration}

The diagnostic minicomputer hardware configuration is illustrated in Fig. 1. The computer system consists of a ModComp Classic computer with $512 \mathrm{~K} 16$-bit words of memory. Devices connected to the computer system include four moving head disks. One 2.5 megabyte cartridge disk is used as the system disk containing fixed partitions of all operating system 1ibraries, tasks, etc. The second 2.5 megabyte cartridge is organized with flexible file structure, using ModComp's File Manager, containing auxiliary files for data analysis tasks. The two large 50 megabyte disks are both file managed disks, containing the current data files for all physics diagnostics for the past 10-20 shots and all system, application and user source and object programs. A high speed bulk core memory contains a portion of the data base accessed frequent$1 y$ and all non-resident services used to manage both the data base and all experimental data. A 6250 cfi tape drive is currently being added to the system, replacing an 800 bpi unit, as the medium for archiving data. The 6250 will reduce the number of tapes generated and increase the speed for archiving the data. A high speed synchronous link to DECsystem-10 is currently being implemented; tapes will then be used only as backup to recover when transmissions between the DECsystem-10 and the ModComp fail.

A communications interface connects 64 devices, both asynchronous and synchronous, to the ModComp. Currently, eighe Tektrunlx Series 4000 graphics terminals are used. In addition, the soft X-ray diagnostic microprocessor system, controlling a commercial multichannel analyzer (MCA) system, interfaces through an RS-232 asynchronous channel. Finally the high speed synchronous link to the DECsystem-10 uses a channel on the communications interface. 


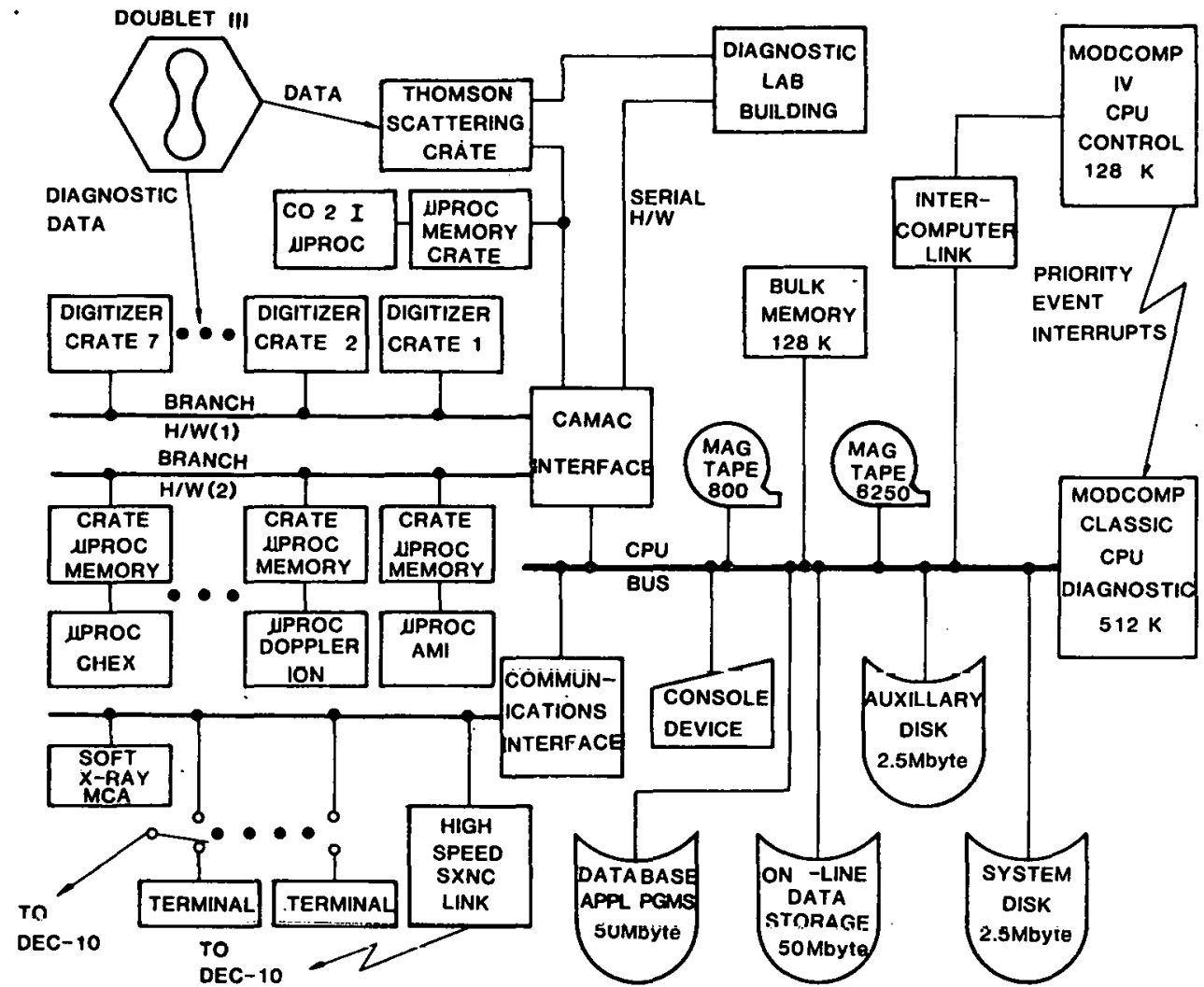

Fig. 1. Host minicomputer hardware configuration 
Most of the diagnostic data acquisition for the Doublet device is performed through a CAMAC system. The Doublet III diagnostic CAMAC system consists of two branch highways and a serial highway. The branch highways, because of their higher transfer rate, contain a majority of the devices producing large data blocks. Two major types of data modules are connected onto the branch highway. LeCroy waveform digitizers, which convert analog signals into digital arrays, are a majority of the data acquisition hardware on the CAMAC system. Currently, a little over 250 channels are being acquired with a future expansion of up to about 500 channels. Most of the digitizers are used to acquire magnetic waveforms, although some diagnostics also utilize this type of data acquisition. The second type of modules predominating on the branch highway are microprocessors with dual port menorfes. Present practice is for each new diagnostic to use a CAMAC microprocessor. system to perform local acquisition and processing. The microprocessor then writes data into its dual port memory with the ModComp acquiring the data over the CAMAC. This distributed processing allows the diagnustic to run independently of the ModComp computer system and also to remove some application processing from the ModComp. The CAMAC serial highway contains all physics diagnostics which require remote capability from the control room. Currently, the Thomson scattering and the $\mathrm{CO}_{2}$ laser interferometer experiments use the serial highway in order to have their interfaces close to their other electronics.

Logging printers $\log$ messages indicating normal operation and abnormal conditions. Error messages to indicate problems in acquisition, processing or archiving of diagnostic data are printed with shot and diagnostic experiment identification. 
Finally, the diagnostic computer system interfaces the control computer system through an intercomputer link and a series of priority interrupts. The control computer is used to control and monttor the operating of the Doublet device. The intercomputer link is used to transfer the data base of the control computer each shot and archive it along with the diagnostic data. The priority interrupts are used by the diagnostic system to synchronize data acquisition, processing and archiving with tokamak operation.

\subsection{Software configuration}

The software system is driven by information organized into a series of files and tables called the data base. The data base is a complete grouping of all information related to the data collected from experiments. on the Doublet device. All system tasks are driven from the data base and include the centralized data acquisition tasks, the data manager responsible for dynamically managing all data locally, the data archiver responsible for transmitting all data to the DECsystem-10, and the task manager responsible for scheduling all system and application tasks. In addition, the experiment application software accesses the data base indirectly in requesting shot data for analysis through the common data file services. Finally, the data base generator and associaced 1nteraclive programs enablc operators to build, view, and modify the data base files and tables.

\section{2 .1 Shot timing.}

The shot cycle on Doublet III from shot initialization through completion is approximately 4-7 minutes. This time span is divided up into a series of time slices, termed phases. Three event times in the shot cycle inftiate sequences of phases causing specific data acquisition tasks to be performed. 
The diagnostic system utilizes these three events to time and initiate all data acquisition, processing and archiving tasks. The first event of a shot cycle, Start Phase (approximately two minutes before a shot), causes the data base files and tables to be initialized, performs calibration of acquisition hardware, initiates the data manager to allocate space for the new data, and performs any acquisition and archiving non-shot dependent data, e.g.; switch settings on acquisition hardware, etc. The second event (occurring ten seconds before a shot) causes all preshot control and acquisition to be performed including initiallzing all transient digitizers and dual port memories, acquiring the control computer's data base, etc. The third event, indicating shot completion, initiates the post shot (data acquisition phases). Since all the Doublet diagnostic data is stored locally in hardware, $1 . e .$, transient digitizers, dual port memories, etc., the computer system simply reads all of the data for a shot and stores it on the data files. To accommodate the large amount of data input per shot, which requires up to two minutes to acquire, the post shot time is divided into ten phases (nine synchronous sequential and one asynchronous). This enables data required for immediate viewing and analysis to be acquired immediately after a shot, while allowing data used for off-1ine analysis to be read later in post shot phases.

\subsubsection{Data acquisition/archiving}

The data acquisition and archiving for the host computer (ModComp) incorporates three decisions. First, all information such as calibration, gain.settings, etc., necessary for analysis must be appended to the data, thus making data structures and programs transferable between computers, Second, all experiments without microprocessors have their data acquired and processed by the host computer. Third, all microprocessors will be polled rather than interrupting the host when data is available. Thus, when a microprocessor has loaded its "mailbox" memory with data, a flag is set and the polling will cause the data to be acquired. 
3. SATELLITE MICROCOMPUTER SYSTEMS

The microprocessor computer systems remove some acquisition and processing work load from the host, providing output soon after a shot is complete. In addition, each diagnostic can be developed, tested, and if necessary operated as an independent system without relying on the host.

\subsection{Microprocessor hardware configuration}

The microprocessor hardware configurations, although different for each application, have a number of common features. Each microprocessor is a CAMAC based LSI-11 processor with $32 \mathrm{~K}$ bytes memory. Floppy disks with $200 \mathrm{~K}$ bytes of storage are used for mass storage. Each micro contains a hardware floating point chip to speed data analysis. Finally, each micro system contains a graphics terminal used to provide application graphics output each shot.

The hardware necessary to interface the micro system to the host computer is done through CAMAC. Each micro system is configured as two CAMAC crates (Fig. 2). One crate contains the microprocessor and all CAMAC, modules necessary to control and acquire data from the experiment and interface the floppy disk, terminal, etc. This crate also contains the physics diagnostic interface which can be either commercially purchased or constructed locally. The second crate is on the host computer's CAMAC. Contalned in this crate is a dual port memory used as a mallbox where micro writes all its data (processed and/or raw) for the host to acquire. 


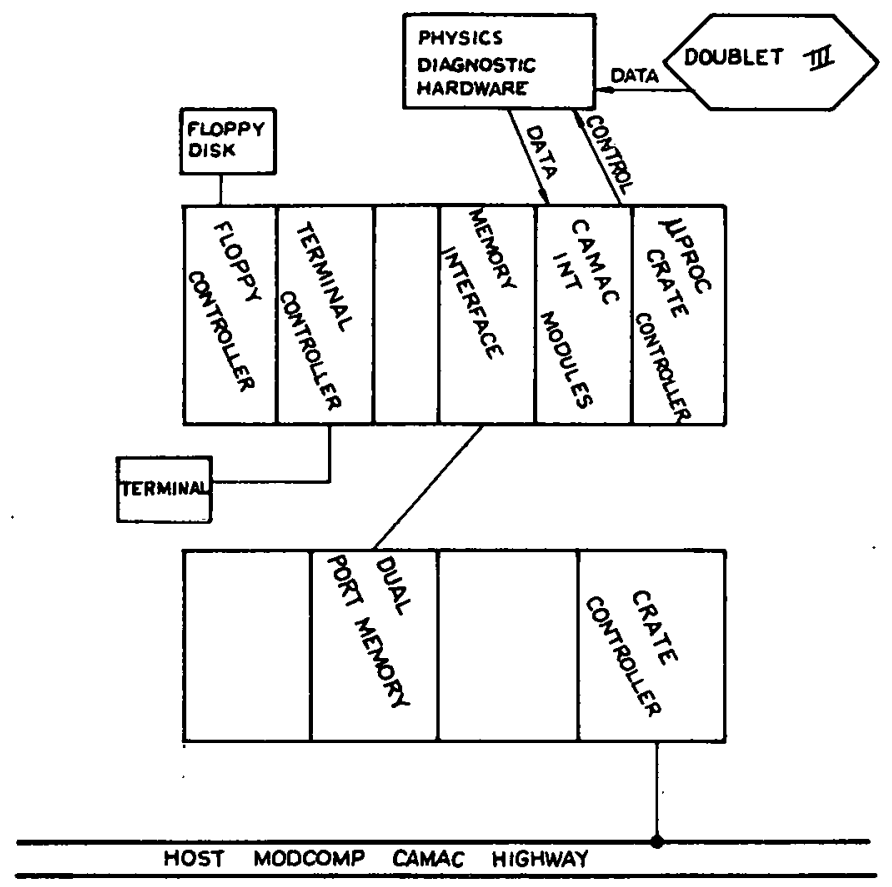

Fig. 2. Microprocessor hardware configuration

\subsection{Software configurations}

The primary software functions of the microprocessors are standard for all and include: 1) providing control of the experiment and acquiring all of the diagnostic data, 2) archiving the data to the host ModComp computer and locally on the floppy disk, and 3) providing initial data reduction, analysis and output thus reducing the work load in the host.

One motive for standardizing on the LSI-1I was the early availability of an adequate operating system for software development in a higher level language. The basic microprocessor configuration supports RT-11, and a somewhat larger LSI-11 work station supports development and maintenance for active diagnostics. FORTRAN, BASIC, MACRO, and PASCAL are available, with FORTRAN predominating. 
The microprocessor software systems are designed to operate in an unattended mode requiring operator intervention to change full floppies and for physicists to examine the shot output to verify correct operation of the diagnostic.

\section{DECSYSTEM-10 COMPUTER}

The purpose of the General Atomic User Service Center (USC) DECsystem-10 computer is threefold. First, the USC provides access to the NMFE large scale central computers ( $\mathrm{CDC}-7600$ and Cray-1) for both the theoretical and experimental investigators at General Atomic requiring such resources. Such large scale requirements arise from the great mathematical complexity of the analysis of the plasma physics problems of interest. Figure 3 shows the overall DECsystem-10 and Doublet III interface to the NMFE computer network.

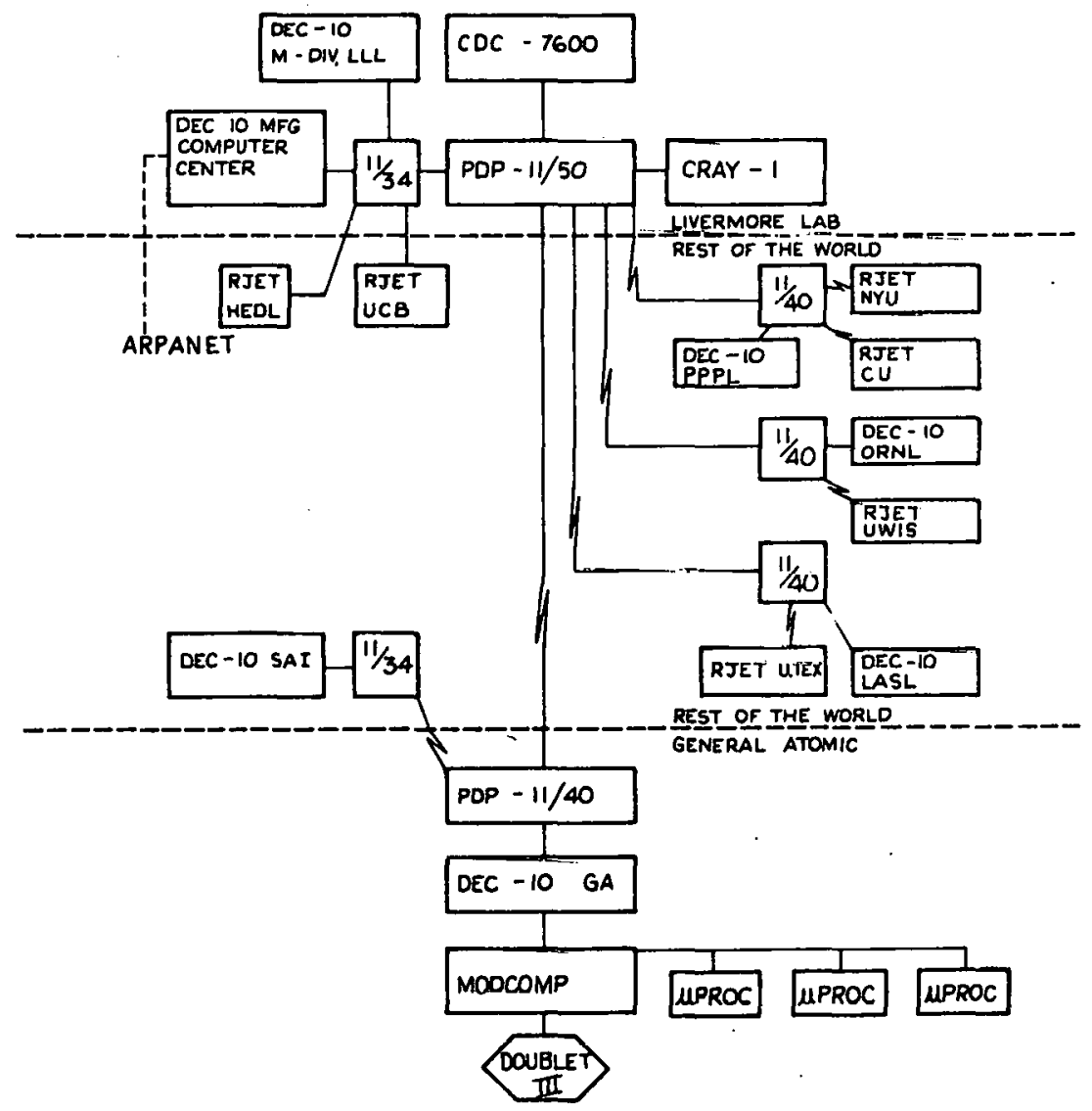

Fig. 3. DECsystem-10 hardware configuration 
The second major task of the USC is to provide data archival, retrieval, and analysis facilities for the Doublet III experiment. Use of the DECsystem-10 for this removes unfavorable interaction of later analysis with data collection and allows use of the proven DECsystem-10 file handling and time-sharing software. The problems of data retrieval and analysis are more concerned with the central processing power of the computer system. A planned upgrade of the USC to dual KL-10 processors is intended to satisfy this requirement so that the analysis of Doublet III data may proceed at a pace determined by the progress of the experiment.

The third task that the USC is used for is local computing unrelated to the Doublet III program. This includes some theoretical plasma physics investigations, engineering and physics calculations related to the Engineering Test Facility program and other DOE Development and Technology tasks.

\subsection{Hardware configuration}

The DECsystem-10 hardware configuration is based upon a model KL-10D central proressnr. Five 200 megabyte disk drives and one 100 megabyte drive are used to contain approximately 100-200 shots of Doublet III data currently being accessed along with all the operating system libraries, source, etc., and system and application programs. Three tape drives are currently in use, processing current Doublet III data, retrieving data already processed and saving systems and Doublet III data for backup. A PDP $11 / 40$ minicomputer provides the synchronous 50K baud link to the NMFE computer center at Lawrence Livermore Laboratory and a 50K baud link to another DECsystem-10 at Science Applications, Inc. A PDP $11 / 40$ with data link hardware provides the $100 \mathrm{~K}$ baud link to the ModComp computer. Two PDP minicomputers (an 11/34 and 11/40) provide 80 asynchronous (300-9600 baud) TTY lines to the DECsystem-10 system to support the high usage of terminals accessing the Doublet III data from throughout the GA facility. An array processor is used by the DECsystem-10 to provide computing power necessary to run suwe of the elaboratc analyels codes processing Doublet III data. Finally, the DECsystem-10 has all the normal high speed peripherals including printers, ploteers, card readers, etc. 


\subsection{Software conflguration}

The DECsystem-10 is responsible for archival and retrieval of all data generated by Doublet III. Data arrives at the DECsystem-10 either on magnetic tape or, in the near future, via a hardwired conmunications link in a form convenient to the ModComp in order to alleviate disk throughput constraints. The data is translated to DECsystem-10 format and archived in a form that may be both conveniently accessed by experImentalists and archived on magnetic tape.

By default, as soon as the data from a shot has been recelved by the DECsystem-10, it is archived on magnetic tape in an easily transportable and retrievable format and deleted from the disk. Only shots which have been explicitly requested by users remain on disk.

Experimentalists may request that shots be restored to the disk interactively. When a shot request is made, a message containing the shot number, magnetic tape reel and the user name is printed on the operator's personal terminal. Response is a few minutes to a few hours depending on the number of shots to be restored. Procedures exist to archive all unarchived shots, restore a shot to disk, bring the number of shots on the disk to a set level and to query the status of any shot.

Users may access data on the DECsystem-10 in one of several ways. ODDBAL, a program developed at the Oak Ridge National Laboratory, emulates an HP45 calculator with data base access capabilities. PLOTER, a code developed at GA on the ModComp, plots data in a variety of ways. MDAT, which does a quick broad spectrum analysis of a given Doublet shot, runs on both the MudCump and the DECsystem-10. Lastly, an MHp code, which is available on the DECsystem-10, the CRAY, the DECsystem-10 array processor and the LLL 7600, is used extensively to investigate plasma current and flux profiles.

*Work supported by the U. S. Department of Energy, Contract No. DE-ATO3-76E'151011 
Internal Distribution

C. Arment rout

L. Campbell

D. Drobnis

J. Garcia

T. Glad

E. Heckman

P. Henline

J. Kamperschroer

S. Karin

J. Kohl1

L. Lertique

J. Luxon

B. McHarg

G. Shephard

R. Stambaugh 